\title{
Localized Unresectable Adult Hepatocellular Carcinoma
}

National Cancer Institute

\section{Source}

National Cancer Institute. Localized Unresectable Adult Hepatocellular Carcinoma. NCI

Thesaurus. Code C9065.

A localized hepatocellular carcinoma that occurs during adulthood and it is not amenable to surgical resection. 